\title{
Recurrent Kidney Wilms Tumor
}

National Cancer Institute

\section{Source}

National Cancer Institute. Recurrent Kidney Wilms Tumor. NCI Thesaurus. Code C7845.

The reemergence of Wilms tumor of the kidney after a period of remission. 